\title{
The effect of cryotherapy on total antioxidative capacity in patients with active seropositive rheumatoid arthritis
}

Hirvonen, $\mathrm{H}$.

2017-09

Hirvonen , H , Kautiainen , H , Moilanen , E , Mikkelsson , M \& Leirisalo-Repo , M 2017 , '

The effect of cryotherapy on total antioxidative capacity in patients with active seropositive rheumatoid arthritis ' , Rheumatology International , vol. 37 , no. 9 , pp. 1481-1487 . https://doi.org/10.1007/s00296-0

http://hdl.handle.net/10138/243929

https://doi.org/10.1007/s00296-017-3771-9

publishedVersion

Downloaded from Helda, University of Helsinki institutional repository.

This is an electronic reprint of the original article.

This reprint may differ from the original in pagination and typographic detail.

Please cite the original version. 


\title{
The effect of cryotherapy on total antioxidative capacity in patients with active seropositive rheumatoid arthritis
}

\author{
H. Hirvonen ${ }^{1}$ H. Kautiainen ${ }^{2,3} \cdot$ E. Moilanen ${ }^{4} \cdot$ M. Mikkelsson ${ }^{5,6}$. \\ M. Leirisalo-Repo ${ }^{1}$ (i)
}

Received: 4 January 2017 / Accepted: 29 June 2017 / Published online: 11 July 2017

(C) Springer-Verlag GmbH Germany 2017

\begin{abstract}
Patients with rheumatoid arthritis (RA) have increased oxidative stress, decreased antioxidant levels, and impaired antioxidant capacity. Cold treatments are used to relieve joint inflammation and pain. Therefore, we measured the effect of cold treatments on the antioxidative capacity of RA patients with active disease. Sixty patients were randomized to (1) whole body cryotherapy at $-110{ }^{\circ} \mathrm{C}$, (2) whole body cryotherapy at $-60{ }^{\circ} \mathrm{C}$, or (3) local cryotherapy. Each treatment was given three times daily for 7 consecutive days in addition to the conventional rehabilitation. Blinded rheumatologist evaluated disease activity before the first and after the last cryotherapy. We collected plasma samples daily immediately before the first and after the second cryotherapy and measured total peroxyl radical trapping antioxidant capacity of plasma (TRAP), which reflects global combined antioxidant capacity of all individual antioxidants in plasma. Baseline morning TRAP levels (mean, 95\%
\end{abstract}

M. Leirisalo-Repo

ext-marjatta.leirisalo-repo@hus.fi

1 Department of Rheumatology, Helsinki University Hospital, University of Helsinki, Helsinki, Finland

2 Department of General Practice, University of Helsinki, Helsinki, Finland

3 Unit of Primary Health Care, Helsinki University Hospital, Helsinki, Finland

4 The Immunopharmacology Research Group, School of Medicine, Tampere University Hospital, University of Tampere, Tampere, Finland

5 Rehabilitation Center, Päijät-Häme Central Hospital, Päijät-Häme Joint Authority for Health and Wellbeing, Lahti, Finland

6 Department of Rehabilitation, Faculty of Medicine and Life Sciences, University of Tampere, Tampere, Finland
CI), adjusted for age, body mass index, disease activity, and dose of prednisolone, were $1244(1098-1391) \mu \mathrm{M} / \mathrm{l}$ in the local cryotherapy, $1133(1022-1245) \mu \mathrm{M} / 1$ in the cryotherapy at $-60{ }^{\circ} \mathrm{C}$, and $989(895-1082) \mu \mathrm{M} / 1$ in the cryotherapy at $-110^{\circ} \mathrm{C}$ groups $(p=0.006)$. After the first treatment, there was a rise in 1-h TRAP of $14.2(-4.2$ to 32.6$) \mu \mathrm{M} / 1,16.1$ ( -7.4 to 39.6$) \mu \mathrm{M} / 1$, and 23.6 (4.143.2) $\mu \mathrm{M} / \mathrm{l}$, respectively. The increase was significant in the whole-body cryotherapy $-110{ }^{\circ} \mathrm{C}$ group $(p<0.001)$ but not significant between the groups $(p=0.78)$. When analyzed for the whole week, the daily morning TRAP values differed significantly between the treatment groups $(p=0.021)$, but there was no significant change within each treatment group. Whole-body cryotherapy at $-110{ }^{\circ} \mathrm{C}$ induced a short-term increase in TRAP during the first treatment session with but not during other treatment modalities. The effect was short and the cold treatments did not cause a significant oxidative stress or adaptation during 1 week.

Keywords Rheumatoid arthritis · Cryotherapy · Antioxidant capacity - Peroxyl radical trapping .

Rehabilitation

\section{Introduction}

Rheumatoid arthritis (RA) is a chronic, progressive autoimmune disease of unknown aetiology characterized by synovitis and progressive joint destruction if untreated. Synovial inflammation is a hallmark of the disease, and infiltration of synovium by inflammatory cells is a major characteristic in the patients. The inflamed synovium containing activated $\mathrm{T}$ cells and macrophages is a milieu favouring the formation of reactive oxygen species. Excessive generation of reactive 
oxygen radicals driven by overproduction of proinflammatory cytokines, in particular TNF and IL-1, participates in inflammatory process and causes degradation of connective tissue molecules, e.g., hyaluronic acid in the synovial fluid and proteoglycans of the synovium, induces lipid peroxidation products and oxidized low-density-proteins, inhibits total protein, proteoglycan and DNA synthesis, and suppresses cellular growth dose-dependently [1-11]. An efficacious antioxidant system including manganese superoxide dismutase, catalase, and glutathione peroxidase type 1 catalyzes the inactivation of reactive oxygen species. Several groups have demonstrated increased oxidative stress along with decreased or inappropriately low antioxidant levels and impaired antioxidant capacity in plasma, in red cells, and in synovial fluids of RA patients [2, 12-15]. The impaired antioxidant capacity also relates to disease activity $[14,15]$.

Application of local cold has long been in use to relieve pain and swelling in different inflammatory and traumatic situations. Regular winter swimming in cold water has reached a great popularity in northern countries to relieve pain and stress and it is believed to induce body hardening resulting in a better tolerance to infections.

An increase in metabolic rate during cold exposition in cold water due to skeletal muscle exercise and hyperventilation has been detected in healthy persons [16]. The increased metabolism would produce a greater amount of toxic oxygen radicals. In resting conditions, healthy habitual winter swimmers have a higher level of reduced glutathione, lower level of oxidized glutathione, and higher levels of superoxide dismutase and catalase in red cells than control persons who are not used to swim in cold water [17]. In habitual winter swimmers, the concentration of oxidized glutathione in red cells is markedly increased $1 \mathrm{~h}$ after the whole-body cold stimulus, while the subjects have a significant decrease in reduced glutathione of red cells and in serum uric acid concentrations without a change of its renal clearance [17]. These results refer to adaptation to repeated oxidative stress [17].

Whole-body cryotherapy was developed in Japan in the late 1970s [18]. In Europe, it has been used since 1984-1985, first in Germany [19]. In whole-body cryotherapy, patients wearing minimal clothing are exposed to very cold and dry air (from $-110{ }^{\circ} \mathrm{C}$ even to $-160{ }^{\circ} \mathrm{C}$ ) in a special unit for 1-3 min. It has been associated with a decrease of pain $[20,21]$ and has been applied especially in Germany to support mobilisation and rehabilitation.

The previous literature describing positive effects of repeated whole-body cold exposure prompted us to study if whole body cryotherapy has an effect on the oxidative stress and antioxidant capacity in RA patients with active disease. The aim of the current investigation was to measure the effect of repeating whole-body cryotherapy at two different temperatures $\left(-110\right.$ or $\left.-60{ }^{\circ} \mathrm{C}\right)$ and local cryotherapy on the antioxidant capacity of RA patients with active disease during an intervention of 1 week. For this, we measured the total peroxyl radical trapping antioxidant capacity of plasma (TRAP), which reflects the global combined antioxidant capacity of all individual antioxidants in plasma [22]. TRAP is a sensitive tool to quantify combined non-enzymatic antioxidant capacity of plasma or tissues. An increase in TRAP is interpreted as increase in antioxidant defence, while a decrease in TRAP shows consumption of antioxidant capacity [23]. Activation of antioxidant defence has been viewed as an adaptive defence mechanism to cope with increased stress [24]. Our hypothesis was that whole-body cryotherapy at $-110{ }^{\circ} \mathrm{C}$ could improve the antioxidant capacity in patients suffering from RA. As control therapies, we studied patients treated with whole body cryotherapy at $-60{ }^{\circ} \mathrm{C}$ or with local cryotherapy.

\section{Patients and methods}

\section{Patients}

The study was carried out in RA patients hospitalized at the Rheumatism Foundation Hospital for treatment and rehabilitation. The patients were informed about the study beforehand and asked to participate in the study.

The patient was eligible for the study if she/he had active seropositive RA. The activity criteria at inclusion were: $\geq 5$ swollen and $\geq 5$ tender joints, erythrocyte sedimentation rate $(\mathrm{ESR}) \geq 20 \mathrm{~mm} / \mathrm{h}$, and/or C-reactive protein (CRP) $>20 \mathrm{mg} / \mathrm{l}$ and the duration of morning stiffness at least for $30 \mathrm{~min}$. The medication had to be stable at least for 1 month before the study and no intra-articular corticosteroid injections had been carried out during the previous month. The exclusion criteria were uncontrolled hypertension (diastolic blood pressure over $100 \mathrm{mmHg}$ ), a history of cardiac arrhythmia, symptomatic cardiovascular or lung disease, severe Raynaud's phenomenon, cold allergy, or cold-induced bronchospasm.

Sixty patients were recruited in the study. They were randomized in three groups, 20 patients in each group: whole-body cryotherapy at $-110{ }^{\circ} \mathrm{C}$, whole-body cryotherapy at $-60{ }^{\circ} \mathrm{C}$. or local cryotherapy (cold packs or cold air $-30{ }^{\circ} \mathrm{C}$ applied to five swollen joints at a time for 10-30 min). Each treatment was given three times daily (at 8:00, 12:00 and 17:00, twice on Sunday) for 7 consecutive days in addition to the conventional rehabilitation. One session of whole-body cryotherapy lasted up to $2 \mathrm{~min}$ and the study continued for 7 days. The total number of exposures was 20 . A blinded rheumatologist $(\mathrm{HH})$ evaluated the number of swollen and tender joints and recorded the physician's global assessment of the patient's disease activity 
(10 $\mathrm{cm}$ visual analogue scale), and recorded the drugs used by the patient before the first and after the last cryotherapy. Disease activity was measured by DAS [25]. The rehabilitation period was from 8 days to 3 weeks, of which the intervention with cold therapy covered the first week, during which the drug therapies were kept stable. After that, the treatments, including glucocorticoid injections in the inflamed joints, could be freely modified.

\section{Cryotherapy}

The patients were randomized to (1) whole-body cryotherapy at $-110{ }^{\circ} \mathrm{C}$, (2) whole-body cryotherapy at $-60{ }^{\circ} \mathrm{C}$, or (3) local cryotherapy. The whole-body cryotherapy was given in a specially built, temperature controlled unit (Zimmer, Elektromedizin). The unit has three chambers, where the patient passes through the first chamber $\left(-10{ }^{\circ} \mathrm{C}\right)$ and the second chamber $\left(-60^{\circ} \mathrm{C}\right)$ before coming into the therapy chamber $\left(-110{ }^{\circ} \mathrm{C}\right)$. During the whole body cryotherapy, the subjects wore bathing suits, surgical masks, caps, gloves, socks, and shoes. In the therapy chamber, the patients were instructed to slightly move their fingers and legs. The adverse effects were documented daily right after the treatment or later on the ward [21].

\section{Blood sampling}

On a treatment day, blood samples were taken before the first cryotherapy (baseline 08:00) and after the second cryotherapy (13:00). Blood samples were taken daily during the 7-day treatment period. On the first day, a sample was also taken $1 \mathrm{~h}$ after the first session of cryotherapy at 09:00. During days 2-7, the blood samples were drawn at 08:00 before first cryotherapy and at 13:00 except on Saturday afternoon and Sunday. No patient started the intervention on Saturday or Sunday. The blood samples were collected in 10-ml EDTA tubes (Becton-Dickinson) kept in fridge before sampling. After the venepuncture, the tubes were protected from light, placed in ice-water, and centrifuged immediately at $+4{ }^{\circ} \mathrm{C}$. The supernatant was divided in aliquots and frozen at $-70{ }^{\circ} \mathrm{C}$. The samples were analyzed within 3 months of sampling.

\section{Total antioxidant capacity (TRAP)}

The antioxidant capacity (total radical-trapping antioxidant parameter, TRAP) of plasma was measured by a chemiluminescence method, as described earlier [26, 27]. In brief, peroxyl radicals are produced at a constant rate by thermal decomposition of 2,2-azo-bis (2-aminopropane) hydrochloride (ABAP; Polysciences, Warrington, PA, USA) in a test tube and peroxyl radical reactions are followed by luminolenhanced chemiluminescence. The time at which the added plasma sample extinguishes the reaction is directly proportional to the peroxyl radical-trapping antioxidative capacity of the sample, i.e.TRAP, which is expressed as micromoles of peroxyl radicals trapped by $1 \mathrm{~L}$ of the sample.

All the patients gave their written informed consent. The study was approved by the ethical committee of PäijätHäme hospital district.

\section{Statistics}

The data are presented as means with standard deviations (SD) or as counts with percentages. Statistical comparison were made using the Chi-square test, analysis of variance (ANOVA) or analysis of covariance (ANCOVA) taking age, body mass index, DAS, and dose of prednisolone as covariates. In the case of violation of the assumptions (e.g., non-normality), a bootstrap-type test was used and 95\% confidence intervals $(95 \% \mathrm{CI})$ were obtained by biascorrected bootstrapping (5000 replications). The bootstrap method is significantly helpful when the theoretical distribution of the test statistic is unknown or in the case of violation of the assumptions. Repeated measures of daily TRAP values in the morning before cold treatments were analyzed generalizing estimating equations (GEE) models with the unstructured correlation structure. No adjustment was made for multiple testing. STATA 14.0, StataCorp LP (College Station, TX, USA) statistical package was used for the analyses.

\section{Results}

Demographic data of the patients are presented in Table 1. All patients had chronic active seropositive RA. Half of the patients were on the conventional DMARDs, and more than half of the patients were on cytostatic treatments (methotrexate or azathioprine) and on low dose prednisolone. No patient was on a biological DMARD. Patients randomized to the local cold therapy had slightly higher disease activity compared with the other patients (Table 1).

Local cryotherapy was well tolerated and accepted. All patients in this treatment category completed the trial and $98 \%$ of the planned cryotherapy sessions were carried out. In both of the whole body cryotherapy groups three patients discontinued during the first 2 days of the intervention because of intolerance and side effects; one patient was withdrawn from the study because of a stable neutropenia present already before entry, regarded as a risk for infective complications. Two more patients in both groups were not included in analysis because of incomplete set of samples. Altogether, 94 and $92 \%$ of the planned cryotherapies were completed in the whole-body cryotherapy at -60 and $-110{ }^{\circ} \mathrm{C}$ treatment arms, respectively. 
Table 1 Baseline demographic, clinical, and radiographic characteristics of patients

\begin{tabular}{|c|c|c|c|c|}
\hline \multirow[t]{2}{*}{ Characteristics } & \multicolumn{3}{|l|}{ Treatment group } & \multirow[t]{2}{*}{$p$ value } \\
\hline & Local cold $(n=20)$ & Cryotherapy $-60^{\circ} \mathrm{C}(n=18)$ & Cryotherapy $-110^{\circ} \mathrm{C}(n=17)$ & \\
\hline \multicolumn{5}{|l|}{ Demographic } \\
\hline Female, $n(\%)$ & $16(80)$ & $16(89)$ & $14(82)$ & 0.75 \\
\hline Age (years), mean (SD) & $58(9)$ & $53(9)$ & $50(9)$ & 0.012 \\
\hline Duration of disease (years), mean (SD) & $16(10)$ & $16(12)$ & $12(10)$ & 0.27 \\
\hline Body mass index $\left(\mathrm{kg} / \mathrm{m}^{2}\right)$, mean (SD) & $25.7(4.3)$ & $24.7(3.7)$ & $29.0(6.1)$ & 0.025 \\
\hline \multicolumn{5}{|l|}{ Clinical } \\
\hline DAS, mean (SD) & $5.14(1.10)$ & $4.28(0.98)$ & $4.59(0.91)$ & 0.033 \\
\hline $\begin{array}{l}\text { Erythrocyte sedimentation rate }(\mathrm{mm} / \mathrm{h}) \text {, mean } \\
\text { (SD) }\end{array}$ & $42(16)$ & $32(19)$ & $38(18)$ & 0.19 \\
\hline C-reactive protein $(\mathrm{mg} / \mathrm{L})$, mean $(\mathrm{SD})$ & $25(23)$ & $31(24)$ & $26(24)$ & 0.73 \\
\hline $\begin{array}{l}\text { Duration of morning stiffness (min), median } \\
\text { (IQR) }\end{array}$ & $120(60,240)$ & $60(60,120)$ & $120(60,120)$ & 0.26 \\
\hline Number of swollen joints, mean (SD) & $19(8)$ & $15(6)$ & $14(7)$ & 0.14 \\
\hline Number of tender joints, mean (SD) & $22(12)$ & $14(8)$ & $19(10)$ & 0.042 \\
\hline $\begin{array}{l}\text { Patient's global assessment (VAS), mm, mean } \\
\text { (SD) }\end{array}$ & $48(28)$ & $37(26)$ & $42(23)$ & 0.47 \\
\hline $\begin{array}{l}\text { Physician's global assessment (VAS), mm, mean } \\
\text { (SD) }\end{array}$ & $46(20)$ & $34(13)$ & $41(18)$ & 0.061 \\
\hline Pain (VAS), mm, mean (SD) & $43(26)$ & $29(26)$ & $46(23)$ & 0.10 \\
\hline Health Assessment Questionnaire, mean (SD) & $1.57(0.80)$ & $1.06(0.55)$ & $1.25(0.65)$ & 0.071 \\
\hline \multicolumn{5}{|l|}{ Radiography } \\
\hline Larsen score (0-100), mean (SD) & $48(38)$ & $43(35)$ & $38(35)$ & 0.71 \\
\hline \multicolumn{5}{|l|}{ Treatment } \\
\hline DMARD, $n(\%)$ & $10(50)$ & $7(39)$ & $8(47)$ & 0.78 \\
\hline Cytostatics, $n(\%)$ & $11(55)$ & $13(72)$ & $10(59)$ & 0.53 \\
\hline Prednisolon, $n(\%)$ & $10(50)$ & $13(72)$ & $8(47)$ & 0.25 \\
\hline Mean dose, mg, mean (SD) & $3.3(0-10)$ & $5.3(0-15)$ & $2.2(0-7.5)$ & 0.049 \\
\hline NSAID, $n(\%)$ & $16(80)$ & $15(83)$ & $15(88)$ & 0.80 \\
\hline
\end{tabular}

$n$ number of patients, DAS disease activity score (van der Heijde et al. [23]), DMARD disease modifying anti-rheumatic drugs (excluding cytostatics), NSAID non-steroidal anti-inflammatory drugs (includes both regular and occasional use)

The baseline TRAP levels before any cryotherapies differed statistically significantly between the groups, when adjusted for age, body mass index, DAS, and dose of prednisolone ( $p=0.006)$ (Fig. 1, left panel). Baseline morning TRAP levels (mean, 95\% CI) were 1244 (1098-1391) $\mu \mathrm{M} / \mathrm{l}$ in the local cryotherapy, $1133(1022-1245) \mu \mathrm{M} / 1$ in the cryotherapy at $-60{ }^{\circ} \mathrm{C}$, and $989(895-1082) \mu \mathrm{M} / \mathrm{l}$ in the cryotherapy at $-110{ }^{\circ} \mathrm{C}$ groups $(p=0.006)$. After the first treatment, there was a rise in 1-h TRAP, respectively. The increase was significant in the whole-body cryotherapy $-110{ }^{\circ} \mathrm{C}$ group $(p<0.001)$. First, we analyzed the change of TRAP during the very first single session of cryotherapy (Fig. 1, right panel). The TRAP increased from baseline within $1 \mathrm{~h}$ in each group; 14.2 ( -4.2 to 32.6$)$ in the local cryotherapy, $16.1(-7.4$ to 39.6) in the cryotherapy at $-60{ }^{\circ} \mathrm{C}$, and $23.6(4.1-43.2)$ in the cryotherapy at $-110{ }^{\circ} \mathrm{C}$ groups. The increase was significant in the whole-body cryotherapy $-110{ }^{\circ} \mathrm{C}$ group $(p<0.001)$ and minor in the other groups. When adjusted for
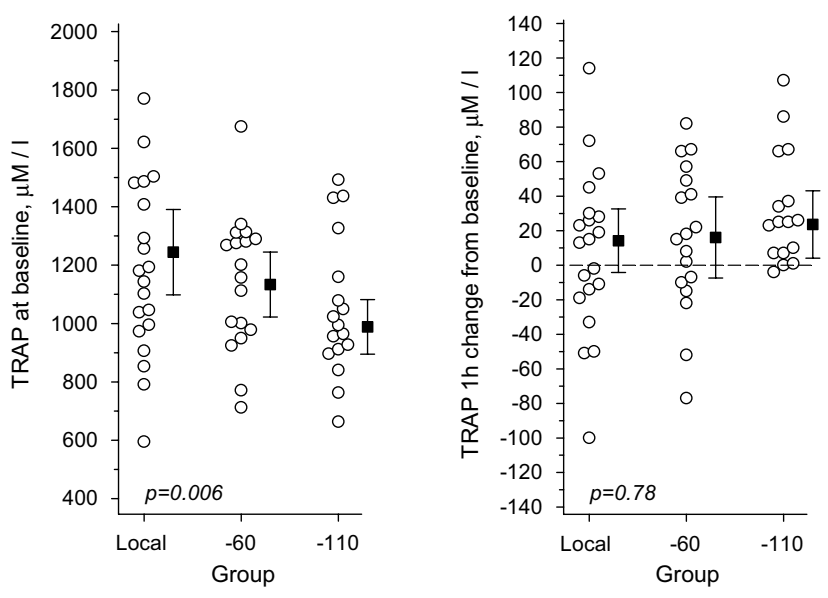

Fig. 1 Baseline TRAP values of each patient according to the treatment groups. Data adjusted for age, body mass index, DAS and dose of prednisolone (left panel), and the change of TRAP, adjusted for age, body mass index, DAS, dose of prednisolone and baseline TRAP (right panel) in one hour after first cryotherapy session. Open circle, single patient, black square, mean with $95 \%$ CIs 
age, body mass index, DAS, dose of prednisolone and basal level of TRAP, the change was not significant between the groups ( $p=0.78)$. Second, we wanted to study if the repeated cold exposure would have a prolonged effect on oxygen radical production and antioxidant capacity during 1 week. Therefore, we analyzed the daily morning TRAP values during the week. When adjusted for age, body mass index, DAS, and dose of prednisolone, the morning TRAP differed significantly between the treatment groups $(p=0.021)$, but there was no statistically significant change in the morning TRAP levels within each treatment group (Fig. 2).

\section{Discussion}

In this study, a rise of TRAP was detected in the first hour of the trial during the first session of cryotherapy in patients treated with cryotherapy at $-110{ }^{\circ} \mathrm{C}$, but not in other treatment groups. We cannot rule out that the small, though significant, detected increase might be due to other patients' characteristics, such as age, body mass index, DAS, dose of prednisolone, or baseline level of TRAP. During the 1-week exposure, there was no adaptation to the cold exposure measured by TRAP. The early transient increase in the TRAP is in line with the results of Dugué et al. [24], who studied TRAP in healthy middle-aged women treated with whole-body cryotherapy at $-110{ }^{\circ} \mathrm{C}$ or with winter swimming three times a week for 12 weeks. In both groups, an immediate (within $2 \mathrm{~min}$ ) increase in TRAP was observed

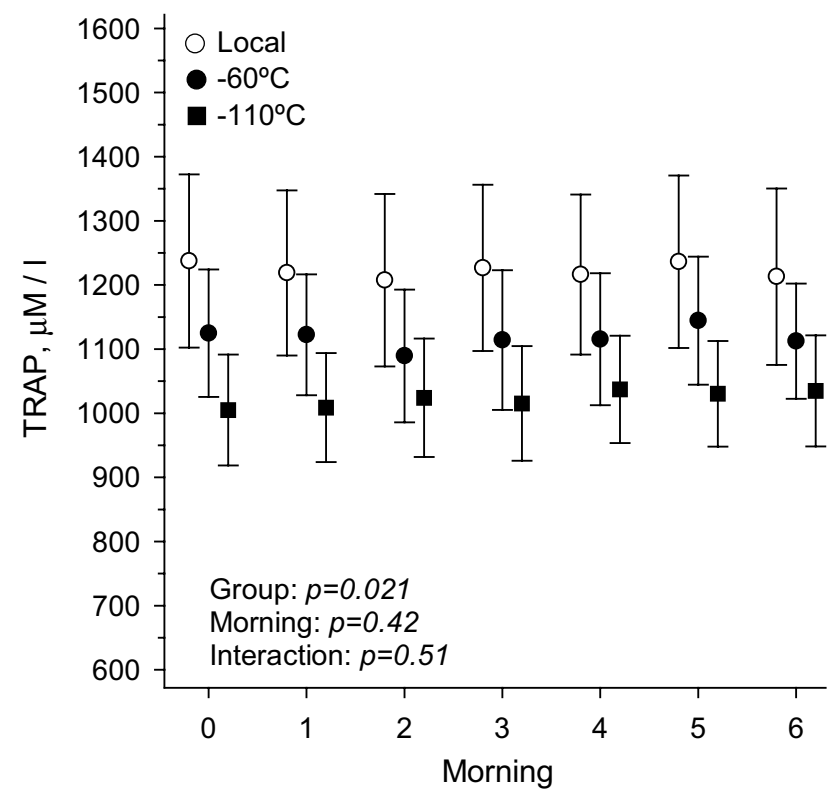

Fig. 2 Baseline TRAP values in the mornings immediately before cold treatment adjusted for age, body mass index, DAS and dose of prednisolone. Treatment groups: open circle, local cold, black circle, $-60^{\circ} \mathrm{C}$, black square $-110^{\circ} \mathrm{C}$. Mean with $95 \% \mathrm{CIs}$ during the first 4 weeks [24]. However, there was no statistically significant increase in the plasma antioxidant capacity when the samples collected $35 \mathrm{~min}$ after cold exposure were compared with the baseline levels [24]. In addition, intensive short-term whole-body cold exposure induced an oxidative stress in habitual winter swimmers [17]. The subjects, when swimming in ice cold water for 5-10 min, had a rapid increase in oxidized glutathione and 4-hydroxynonenal levels (observed in $15 \mathrm{~min}$ ) and a rapid fall in reduced glutathione, urate, and ascorbic acid levels (observed within $1 \mathrm{~h}$ ), indicating that acute cold stress induced an oxidative stress in the swimmers [17]. Evidently, the oxidative stress is very short. During the 7-day cryotherapy treatment, when we measured TRAP before the first cold treatment and $5 \mathrm{~h}$ later, exposure to even whole-body cryotherapy at $-110{ }^{\circ} \mathrm{C}$ did not cause a significant prolonged change in TRAP.

Interestingly, while there was no change in the clinical activity or inflammatory variables during the 7-day treatment period [21], we reported a significant decrease in pain especially in patients treated with cryotherapy at $-110^{\circ} \mathrm{C}$, as reported also by others $[20,28,29]$. The 7 -day treatment might have been too short for the suppression of disease activity or to show any mid-term or long-term effect. Because of active disease, we considered unethical to extend the time period of cold treatment while keeping the drug therapy unchanged for more than 7 days. Recently, rehabilitation using cold treatments including cold chamber therapy and local cryotherapy during a rehabilitation period of 3 weeks was reported to result in greater improvement in disease activity and function in RA patients compared with the traditional rehabilitation [30].

Cold either used as local cooling of inflamed joints or other ways, such as winter swimming, have been used by patients to suppress joint pain and stiffness. In healthy middle-aged women with no previous experience in winter swimming or whole body cryotherapy, treatment with whole body cryotherapy at $-110{ }^{\circ} \mathrm{C}$ or with winter swimming three times a week for 12 weeks resulted in sustained increase in plasma norepinephrine, while epinephrine was unchanged, and plasma ACTH and cortisol levels in weeks 4-12 were significantly lower than at start [31]. According to the authors, the frequent increase in norepinephrine during the cold exposure might have a role in pain alleviation.

TRAP reflects the global combined antioxidant capacity of all individual antioxidants in blood. The main known components of it are uric acid, ascorbic acid, tocopherol, and plasma SH-groups. Besides those, there is an unidentified fraction which cannot be classified more exactly [32]. Interestingly, erythrocyte superoxide dismutase, catalase, and reduced glutathione levels are higher and oxidized glutathione levels are lower in healthy habitual winter swimmers compared with healthy controls [17] indicating an improved antioxidative 
protection and an adaptation in cold. The same subjects, when swimming in ice cold water for 5-10 min, had a rapid fall in reduced glutathione, urate and ascorbic acid levels, and a rapid increase in oxidized glutathione and 4-hydroxynonenal levels [17], indicating that despite of adaptation, the acute cold stress induced an oxidative stress in the swimmers. Because the exposure to cold in winter swimmers in studies by Siems et al. [17] and Dugué et al. [24] was short, the adaptation and response to oxidative stress was most probably related to the cold exposure itself and less probably related to the exercise. In the current study, we measured the total antioxidative capacity, not the concentrations of the known components of TRAP. The total co-operative action of the human antioxidative system in vivo can be different from that of a single agent.

There was a great variation of TRAP values between single patients in this study. In the present study, we did not have healthy control subjects. However, individual values were within the range of Finnish healthy middle-aged women reported by Dugué et al. [24]. They did not observe any significant change at any time point in the resting values of TRAP in 35-45-year-old healthy women without previous experience in winter swimming or whole-body cryotherapy who were exposed to whole-body cryotherapy three times in a week during 12 weeks [24]. Age, sex, disease activity, immobility, and medications can have an effect on TRAP values [22, 24, 27, 33], with TRAP increasing especially in women with increasing age. There was an increase in TRAP during the first hour of cryotherapy in those randomized to the $-110{ }^{\circ} \mathrm{C}$, but not in the other patients. Unfortunately, our randomized groups were not identical in baseline statistics. The patients in the $-110{ }^{\circ} \mathrm{C}$ treatment group were younger compared with the other groups (Table 1) and started from a slightly lower level (Fig. 1). Many disease-modifying anti-rheumatic drugs (DMARDs) can have an effect on free radical production, on the antioxidative capacity or on the function of free radical scavengers [34-37]. Glucocorticoids have profound effects on polymorphonuclear leucocytes, which produce reactive oxygen radicals. In the present study, there were not significant differences between the groups in the use of prednisolone and DMARDs.

We conclude that cold treatments induced a short-term increase in TRAP in patients with active RA during the first treatment session with whole-body cryotherapy at $-110{ }^{\circ} \mathrm{C}$ but not during other treatment modalities. The effect was short and the cold treatments did not cause significant oxidative stress or adaptation as measured by TRAP in seropositive RA patients with active arthritis who used local or whole-body cryotherapy two or three times daily during 1 week. Cryotherapy as used in this study seems to be well tolerated and safe.

\section{Compliance with ethical standards}

Disclosures The authors declare that they have no conflict of interest relevant to the content of this work.

Funding The study was funded by the Finnish Social Insurance Institution.

Conflict of interest Marjatta Leirisalo-Repo, Hanna Hirvonen, Hannu Kautiainen, Eeva Moilanen, and Marja Mikkelsson declare that they have no conflict of interest.

\section{References}

1. Greenwald RA (1991) Oxygen radicals, inflammation, and arthritis: pathophysiological considerations and implications for treatment. Semin Arthritis Rheum 20:219-240

2. Hitchon CA, El-Gabalawy HS (2004) Oxidation in rheumatoid arthritis. Arthritis Res Ther 6:265-278

3. Afonso V, Champy R, Mitrovic D, Collin P, Lomri A (2007) Reactive oxygen species and superoxide dismutases: role in joint diseases. Jt Bone Spine 74:324-329

4. Schenck P, Schneider S, Miehlke R, Prehm P (1995) Synthesis and degradation of hyaluronate by synovia from patients with rheumatoid arthritis. J Rheumatol 22:400-405

5. Baker M, Feigan J, Lowther A (1989) The mechanism of chondrocyte hydrogen peroxide damage. Depletion of intracellular ATP due to suppression of glycolysis caused by oxidation of glyceraldehyde-3-phosphate dehydrogenase. J Rheumatol 16:7-14

6. Vincent F, Brun H, Clain E, Ronot X, Adolphe M (1989) Effects of oxygen-free radicals on proliferation kinetics of cultured rabbit articular chondrocytes. J Cell Physiol 141:262-266

7. Schalkwijk J, van den Berg W, van de Putte L, Joosten L (1985) Hydrogen peroxide suppresses the proteoglycan synthesis of intact articular cartilage. J Rheumatol 12:205-210

8. Bates E, Lowther D, Handley C (1984) Oxygen free-radicals mediate an inhibition of proteoglycan synthesis in cultured articular cartilage. Ann Rheum Dis 43:462-469

9. Greenwald R, Moy W (1980) Effect of oxygen-derived free radicals on hyaluronic acid. Arthritis Rheum 23:455-463

10. Panasyuk A, Frati E, Ribault D, Mitrovic D (1994) Effect of reactive oxygen species on the biosynthesis and structure of newly synthesized proteoglycans. Free Radic Biol Med 16:157-167

11. Bashir S, Harris G, Denman M, Blake D, Winyard P (1993) Oxidative DNA damage and cellular sensitivity to oxidative stress in human autoimmune diseases. Ann Rheum Dis 52:659-666

12. Öztürk HS, Çimen MYB, Kaçmaz M, Durak Î (1999) Oxidant/ antioxidant status of plasma samples from patients with rheumatoid arthritis. Rheumatol Int 19:35-37

13. Schett G, Tohidast-Akrad M, Steiner G, Smolen J (2001) The stressed synovium. Arthritis Res 3:80-86

14. Hassan SZ, Gheita TA, Kenawy SA, Fahim AT, El-Sorougy IM, Abdou MS (2011) Oxidative stress in systemic lupus erythematosus and rheumatoid arthritis patients: relationship to disease manifestations and activity. In J Rheum Dis 14:325-331

15. Sarban S, Kocyigit A, Yazar M, Isikan UE (2005) Plasma total antioxidant capacity, lipid peroxidation, and erythrocyte antioxidant enzyme activities in patients with rheumatoid arthritis and osteoarthritis. Clin Biochem 38:981-986

16. Hayward JS, Eckerson JD, Collis ML (1977) Thermoregulatory heat production in man: prediction equation based on skin and 
core temperatures. J Appl Physiol Respir Environ Exerc Physiol 42:377-384

17. Siems WG, Brenke R, Sommerburg O, Grune T (1999) Improved antioxidative protection in winter swimmers. Q J Med 92:193-198

18. Yamauchi T, Kim S, Nogami S, Abe D, Kawano Y (1981) Extreme cold treatment $\left(-150{ }^{\circ} \mathrm{C}\right)$ on the whole body in rheumatoid arthritis. In: ILAR XVth international congress of rheumatology, Paris, 21-27 June 1981 (abstract Rev Rhum 48(suppl):P1054)

19. Fricke R (1989) Ganzkörperkältetherapie in einer Kältekammer mit Temperaturen um $-110^{\circ} \mathrm{C}$. Z Phys Baln Med Klim 18:1-10

20. Metzger D, Zwingmann C, Protz W, Jäckel WH (2000) Wholebody cryotherapy in rehabilitation of patients with rheumatoid arthritis. Rehabilitation (Stuttg) 39:93-100

21. Hirvonen HE, Mikkelsson MK, Kautiainen H, Pohjolainen TH, Leirisalo-Repo M (2006) Effectiveness of different cryotherapies on pain and disease activity in active rheumatoid arthritis. A randomised single blinded controlled trial. Clin Exp Rheumatol 24:295-301

22. Aejmelaeus R, Metsä-Ketelä T, Pirttilä T, Hervonen A, Alho H (1997) Unidentified antioxidant defences of human plasma in immobilized patients: a possible relation to basic metabolic rate. Free Radic Res 26:335-341

23. Pinho RA, Chiesa D, Mezzomo KM, Andrades ME, Bonatto F, Gelain D, Dal Pizzol F, Knorst MM, Moreira JC (2007) Oxidative stress in chronic obstructive pulmonary disease patients submitted to a rehabilitation program. Respir Med 101:1830-1835

24. Dugué B, Smolander J, Westerlund T, Oksa J, Nieminen R, Moilanen E, Mikkelsson M (2005) Acute and long-term effects of winter swimming and whole-body cryotherapy on plasma antioxidative capacity in healthy women. Scand J Clin Lab Invest 65:395-402

25. van der Heijde DM, van 't Hof M, van Riel PL, van de Putte LB (1993) Development of a disease activity score based on judgment in clinical practice by rheumatologists. J Rheumatol 20:579-581

26. Metsä-Ketelä T (1991) Luminescent assay for total peroxyl radical-trapping capability of plasma. In: Stanley P, Kricka L (eds) Bioluminescence and chemiluminescence. Current status. Wiley, Chichester, pp 389-392

27. Aejmelaeus TR, Holm P, Kaukinen U, Metsä-Ketelä TJA, Laippala P, Hervonen ALJ, Alho HER (1997) Age-related changes in the peroxyl radical scavenging capacity of human plasma. Free Radic Biol Med 23:69-75
28. Braun KP, Brookman-Amissah S, Geissler K, Ast D, May M, Ernst H (2009) Ganzkörperkryotherapie be Patienten mit entzündlich-rheumatischen Erkrankungen. Med Klin (Munich) 104:192-196

29. Guillot X, Tordi N, Mourot L, Demougeot C, Dugué B, Prati C, Wendling D (2014) Cryotherapy in inflammatory rheumatic diseases: a systematic review. Expert Rev Clin Immunol 10:281-294

30. Księżopolska-Orłowska K, Pacholec A, Jędryka-Góral A, Bugajska J, Sadura-Sieklucka T, Kowalik K, Pawłowska-Cyprysiak K, Łastowiecka-Moras E (2016) Complex rehabilitation and the clinical condition of working rheumatoid arthritis patients: does cryotherapy always overtop traditional rehabilitation? Disabil Rehabil 38:1034-1040

31. Leppäluoto J, Westerlund T, Huttunen P, Oksa J, Smolander J, Dugué B, Mikkelsson M (2008) Effects of long-term wholebody cold exposures on plasma concentrations of ACTH, betaendorphin, cortisol, catecholamines and cytokines in healthy females. Scand J Clin Lab Invest 68:145-153

32. Aejmelaeus R (1997) The total radical scavenging capacity of human plasma and LDL: effect of age and disease. Dissertation. University of Tampere, National Public Health Institute Helsinki

33. Aejmelaeus R, Metsä-Ketelä T, Laippala P, Alho H (1996) Is there an unidentified defence mechanism against infection in human plasma? FEBS Lett 384:120-130

34. Joshi R, Kumar S, Unnikrishnan M, Mukherjee T (2005) Free radical scavenging reactions of sulfasalazine, 5-aminosalicylic acid and sulfapyridine: mechanistic aspects and antioxidant activity. Free Radic Res 39:1163-1172

35. Grootveld M, Blake DR, Sahinoglu T, Claxson AW, Mapp P, Stevens C, Allen RE, Furst A (1990) Control of oxidative damage in rheumatoid arthritis by gold(I)-thiolate drugs. Free Radic Res Commun 10:199-220

36. Vuolteenaho K, Kujala P, Moilanen T, Moilanen E (2005) Aurothiomalate and hydroxychloroquine inhibit nitric oxide production in chondrocytes and in human osteoarthritic cartilage. Scand J Rheumatol 34:475-479

37. Túnez I, Feijóo M, Huerta G, Montilla P, Muñoz E, Ruíz A, Collantes E (2007) The effect of infliximab on oxidative stress in chronic inflammatory joint disease. Curr Med Res Opin 23:1259-1267 